\title{
Memorias del III Simposio Nacional y I Internacional de Actualización e Investigación en Ciencias Biomédicas
}

La Revista NOVA en formato electrónico publica los resúmenes de las conferencias magistrales de los módulos de genética, bioquímica, bioinformática, microbiología, parasitología, bioética y los resúmenes de los trabajos libres.

En formato impreso encontrará las memorias publicadas así:

1. En el volumen 4: Resúmenes de trabajos libres.

2. En el volumen 5: Resúmenes de conferencias de los módulos de genética, bioquímica y bioinformática.

3. En el volumen 6: Resúmenes de las conferencias de los módulos de microbiología, parasitología y bioética.

Este evento se llevó acabo en el mes de agosto de 2005 y fue organizado por la Universidad de la Sabana, la Universidad Colegio de Cundinamarca, la Universidad de Los Andes, la Universidad INCCA de Colombia, la Asociación Colombiana de Genética Humana Grupo de Mutagénesis y Carcinogénesis y la Asociación Colombiana de Ciencias Biológicas. Información adicional: escribanos a revistanova@unicolmayor.edu.co

\section{Resúmenes de Trabajos Libres}

1.

\section{Actividad bloqueadora de la transmisión en una zona endémica para malaria por} Plasmodium vivax.

Autores: Myriam Arévalo-Herrera, Yezid Solarte, Felipe Zamora, Fabián Méndez, María Fernanda Yasnot, Leonardo Rocha, Carole Long, Louis H. Millar y Sócrates Herrera.

Institución: Instituto de Inmunología del Valle, Universidad del Valle. Correo Electrónico: feli31@hotmail.com

Palabras claves: Malaria, Bloqueo de la transmisión, Plasmodium vivax, Anopheles

Resumen: La actividad bloqueadora (TB) de la transmisión para Plasmodium vivax en Anopheles albimanus fue evaluada en sueros de pacientes agudamente enfermos, provenientes de la costa pacifica colombiana. Se evaluó la reducción en el número de ooquistes en el estomago del mosquito Anopheles alimentados artificialmente con glóbulos rojos infectados proveniente de estos pacientes. De los 88 lotes que desarrollaron la infección cuando los eritrocitos infectados fueron reconstituidos con suero humano $\mathrm{AB}$ control, cerca de un tercio (36.4\%) mostraron máxima actividad bloqueadora (=90\% inhibición) cuando fue mezclada con el suero autólogo, el 29.6\% presento un TB parcial (50\% a $89 \%$ ), y los sueros restantes no presentaron bloqueo $(17.0 \%$ tuvieron entre $0 \%$ a $50 \%$ de inhibición) o aumento de la transmisión (17.0\%). La actividad bloqueadora de la transmisión se correlacionó con el título de anticuerpos por inmunofluorescencia (IFI) contra las formas sanguí- neas del parásito. Los afro-colombianos presentaron menor TB que los otros grupos étnicos y los pacientes con fiebre produjeron una mayor inhibición de la transmisión que los pacientes sin fiebre.

\section{2.}

\section{Evaluación de la calidad microbiológica del agua del Humedal de Jaboque, Bogota, Colombia.}

Autores: Sara Ávila de Navia, Mónica Estupiñán Torres. Instituciones: Universidad Colegio Mayor de Cundinamarca. Facultad de Ciencias de la Salud. Programa de Bacteriología y Laboratorio Clínico. Correspondencia: savila@unicolmayor.edu.co Palabras claves: calidad del agua, humedales, indicadores microbiológicos.

Resumen: El humedal de Jaboque ha reducido su extensión producto de la construcción de canales de aguas lluvias y negras, ha presentado colmatación debido a la carga orgánica, basuras y desechos de construcción, el espejo de agua se encuentra reducido y, por lo tanto, las áreas necesarias para la alimentación de las especies nativas se encuentran afectadas. La vegetación típica esta siendo reemplazada por especies introducidas por el hombre para favorecer la ganadería. Determinar el riesgo de contaminación tanto a nivel humano como ambiental y conocer el tipo de microorganismos presentes y su concentración, permitirá la toma de decisiones sobre control de vertidos, tratamiento del agua y conservación del ecosistema. En el presente tra- 
bajo se buscó evaluar la calidad sanitaria de las aguas del Humedal de Jaboque por medio de los indicadores de aguas residuales y otros grupos bacterianos como Pseudomonas y Aeromonas. Se tomaron trece muestras de agua superficial distribuidas en la zona canalizada y no canalizada del humedal, para evaluar posibles variaciones temporales se realizaron muestreos en épocas de verano e invierno. La técnica utilizada para el análisis bacteriológico del agua fue filtración por membrana, para este estudio se realizó el recuento de coliformes totales, Aeromonas, Entero-coccus, Pseudomonas y Clostridium. La identificación de los microorganismos aislados se realizó por medio de pruebas bioquímicas rápidas Crystal BBL y API-20 Biomerieux. Se encontró que no existen diferencias significativas entre los recuentos obtenidos en las estaciones de muestreo para todos los grupos bacterianos, sin embargo, si existen diferencias significativas entre las abundancias de las especies aisladas y los recuentos de las especies en cada una de las estaciones de muestreo. Los grupos de mayor abundancia fueron coliformes totales, Aeromonas y Pseudomonas. Se determinó que la concentración de bacterias indicadoras de contaminación fecal es muy alta, lo que implica un alto riesgo sanitario para las personas que habitan los alrededores. Así mismo, se identificaron una gran variedad de microorganismos, que muestran la diversidad bacteriana y brindan información para su posible utilización en el campo de la biotecnología y la indicación biológica.

\section{3.}

\section{Detección de ralstonia solanacearum en papa, mediante la comparación de técnicas diagnosticas inmunoenzima- ticas con técnicas de diagnóstico molecular.}

\footnotetext{
Autores: ${ }^{1-2}$ Edisson Chavarro Mesa, ${ }^{1-2}$ Jorge Evelio Ángel Díaz y 1-2 $^{1-2}$ Julián Martínez Henao

Instituciones: ${ }^{1}$ Universidad INCCA de Colombia, ${ }^{2}$ Laboratorio Nacional de Análisis Molecular del Instituto Colombiano Agropecuario ICA, Seccional Cundinamarca - Mosquera, Colombia.

Correspondencia: bioedicha@gmail.com

Palabras clave: Ralstonia solanacearum, Pseudomonas solanacearum, dormidera, Solanum phureja, PCR,ELISA-NCM, marchitez bacteriana.
}

Resumen: La detección de Ralstonia solanacearum representa un problema en el control de la marchitez bacteriana de la papa, debido a la falta de métodos rápidos y precisos para diagnosticar de forma rutinaria al patógeno. La presencia de $R$. Solanacearum es un riesgo para la producción, fundamentalmente de los tubérculos destinados a semilla. El objetivo del presente trabajo fue adoptar una metodología inmunoenzimática y/o la verificación de diagnóstico molecular de rutina de alta especificidad y sensibilidad; basada en una técnica estandarizada, confiable y rápida que permita confirmar resultados preliminares para la detección de $R$. solanacearum en tubérculos y plantas de papa. El patógeno se aisló a partir de tubérculos de Solanum phureja empleando técnicas de cultivo, pruebas inmunológicas (NCM-ELISA) y prueba molecular (PCR). Tres métodos fueron estandarizados para la extracción de ADN bacterial, dos protocolos para la obtención de $\mathrm{ADN}$ total a partir de cultivos líquidos puros de la bacteria, el tercer protocolo se desarrollo hirviendo el cultivo liquido puro. Estos resultados indicaron que dos de los tres métodos ensayados son los mas adecuados para ser implementados en él diagnostico molecular de $R$. solanacearum. La prueba inmunoenzimática, ELISA-NCM fue positiva para el análisis de 8 submuestras compuestas de 25 tubérculos cada una, que fueron confirmados por PCR. El estudio de aislamientos a partir de material vegetal, que fueron evaluados por metodología de PCR mediante el uso de iniciadores específicos que reconocen las regiones $16 \mathrm{~S}$ rADN, presenta un producto de amplificación reproducible de 292 $\mathrm{pb}$. Los resultados mostraron que se dispone de una técnica sensible para la detección de $R$. solanacearum que puede ser implementada como un método de control de la bacteria en programas de producción de semilla y certificación de áreas libres del patógeno. 
4.

\section{Efecto de la Rosiglizatona y Telmisartan en la diferenciación de células adiposas}

\author{
Autores: Diana Vargas Trujillo y Fernando Lizcano Losada \\ Instituciones: Universidad de La Sabana. Facultad de Medicina. \\ Laboratorio de Biología Molecular \\ Correspondencia: dianavt@unisabana.edu.co \\ Palabras claves: diferenciación células adiposas, PPARg, agonistas.
}

Resumen: Los adipocitos son células multipotentes de origen mesodérmico altamente especializadas que cumplen un papel fundamental en la homeostasis del organismo; dado que durante el proceso de diferenciación deben activarse los diferentes genes que regulan el metabolismo lipídico incluyendo transporte de ácidos grasos, B-oxidación, almacenamiento y funciones de regulación de ingesta y gasto energético se hace importante conocer el mecanismo a través del cual células tipo fibroblasto se diferencian en adipocitos maduros ya que alteraciones durante este proceso están asociadas a enfermedades como el síndrome metabólico; gracias a los buenos modelos de líneas celulares existentes para estudiar la diferenciación de las células adiposas, hemos utilizado para este estudio fibroblastos unipotentes 3T3-L1 para inducir diferenciación con dos medicamentos, Rosiglitazona y Telmisartan los cuales son agonistas del receptor nuclear PPAR, factor de la transcripción encargado de activar los genes que regulan el metabolismo lipídico incluyendo transporte de ácidos grasos, B-oxidación, almacenamiento y funciones de regulación de ingesta y gasto energético. Encontrándose que las células 3T3-L1 tratadas con rosiglitazona inducen aproximadamente 2 veces más la adipogénesis que las células tratadas con Telmisartan. Al realizar los experimentos de transfección se observó que La actividad de luciferasa es 2 veces mayor con Rosiglitazona que con Telmisartan cuando actúa sobre el elemento de respuesta PPRE-Luc. Al aumentar la dosis de Telmisartan (10mM) la transactivación de PPARg es mayor pero no igual al efecto ejercido por Rosiglitazona aún en una dosis menor; corroborando así el agonismo parcial de Telmisartan sobre PPARg.
Lo que permite concluir que Telmisartan actúa como un agonista parcial de PPARg en comparación al efecto que tiene Rosiglitazona sobre este factor de la transcripción. A pesar que no es conocido en su totalidad el mecanismo a través del cual actúan estos medicamentos, el agonismo parcial sobre PPARg podría ser un blanco de estudio ya que no produce los efectos secundarios generados por el agonismo total.

5.

\section{Caracterización de los sitios de multiplicación de Aedes aegypti (Diptera: Culicidae) en una zona del municipio de Fusagasuga y la utilización de marcadores moleculares para el análisis del vector}

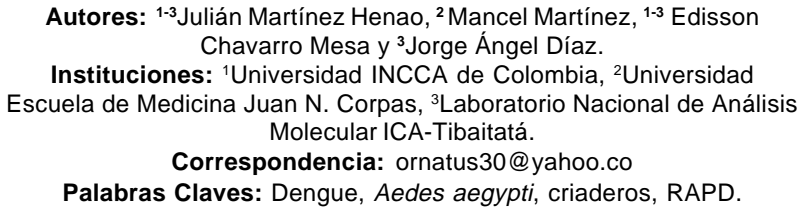
Molecular ICA-Tibaitatá. Correspondencia: ornatus30@yahoo.co Palabras Claves: Dengue, Aedes aegypti, criaderos, RAPD.

Resumen: Entre los factores más importantes en el fracaso de campañas destinadas a controlar o eliminar culícidos urbanos están el aumento en el número de criaderos generados por la actividad humana, consecuencia de patrones culturales y tradicionales; además de las deficiencias en los servicios públicos básicos como el abasto de agua y la recolección de desechos sólidos, así como el escaso conocimiento existente sobre la ecología de los culícidos urbanos. La aparición de epidemias de dengue y dengue hemorrágico en el área del caribe, obliga a revisar la información sobre la situación de cría de Aedes aegypti en la zona, con objeto de tomar iniciativas globales de control. En este trabajo se realizo la búsqueda activa y caracterización de criaderos intra y peri domiciliarios en el barrio el Lucero y el Progreso de la comuna norte del municipio de Fusagasuga. Se visitaron 145 casas escogidas mediante un muestreo aleatorio simple, se realizó una encuesta identificando los factores de riesgo para la presencia del vector y se efectuó una búsqueda activa de 
larvas e insectos adultos. En el $14.9 \%$ y el $12 \%$ de las casas del barrio el Lucero y el Progreso se encontraron larvas de culícidos las cuales intentaron asociarse con las características encontradas en las viviendas. Los datos de las encuestas se analizaron mediante el programa Epiinfo 2004, realizando un análisis de casos y controles. Las larvas encontradas fueron identificadas en el laboratorio utilizando claves dicotomícas, y fueron analizadas mediante la utilización de marcadores moleculares RAPD los cuales permiten establecer un perfil molecular diferencial que corrobora la identificación morfológica de las especies y permite realizar observaciones importantes sobre la similaridad genética de los vectores.

\section{6.}

\section{Evaluación diagnóstica de fracciones proteícas de 92, 53, 39 y $12 \mathrm{kDa}$ aisladas a partir de extractos crudos de metacéstodos de Taenia solium frente a saliva de pacientes con Neurocisticercosis}

Autores: Habib Yanine, Julio César Giraldo, Reinel Vásquez, Tomás Zamora, Juan Carlos Casas. Instituciones: Universidad Incca de Colombia, Universidad del Cauca.

Correspondencia: jcesargiraldo@hotmail.com. Palabras Clave: neurocisticercosis, ELISA, saliva.

Resumen: Para evaluar el desempeño diagnóstico de fracciones proteicas de larvas de Taenia solium y la combinacion de las mismas en el diagnóstico de NCC, se estandarizó un ensayo inmunoenzimático ELISA indirecto con las fracciones de 12, 39, 53 y 92kDa, mediante diseño de casos y controles, que permitió también establecer factores de riesgo (odds ratio) para la enfermedad. El mejor comportamiento diagnóstico en saliva lo presentó la fracción $12 \mathrm{kDa}$ con $72,72 \%$ de sensibilidad, $100 \%$ de especificidad, seguida por la de $53 \mathrm{kDa}$ con $56,52 \%$ de sensibilidad y $77,77 \%$ de especificidad. En suero el mejor desempeño lo presentó la fracción de $53 \mathrm{kDa}$ con $66,6 \%$ de sensibilidad y $100 \%$ de especificidad. El uso de mezclas de fracciones proteicas no presentó parámetros diagnósticos supe- riores a su uso individual. Los casos presentaron en su mayoría NCC inactiva 95.8\%(23/24), siendo la edad promedio para los casos y controles de $40+/-16.06$ y $44,6+/-20.82$ años respectivamente $(p=0.406)$. En ambos grupos se observó un mayor porcentaje de mujeres (75\% para casos, 68,4 para controles, $\mathrm{p}=0.398$ ). En cuanto a rangos de edades, se observó diferencia significativa $(\mathrm{p}=0.046)$ para los grupos de 21 a 30 años y 31 a 40 años, donde prevalecían los casos sobre los controles. Como riesgos clínicos se identificaron la cefalea, convulsiones, vómito, visión borrosa y epilepsia de inicio tardío. En cuanto a factores epidemiológicos se identificaron como riesgos: el contacto con personas teníasicas, antecedentes familiares de teníasis, lavado poco recuente de manos, nivel superior de educación, el preparar sus propios alimentos y el tener ocupaciones como ama de casa, educador, comerciante y trabajar en el área administrativa, factores que apoyaron la hipótesis de una fuente de infección fuera del núcleo familiar.

\section{7.}

\section{Frecuencias alélicas y haplotípicas del sistema HLA ABDR en Colombia}

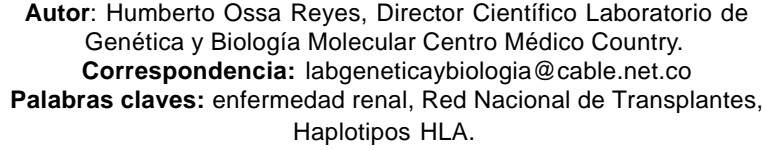

Autor: Humberto Ossa Reyes, Director Científico Laboratorio de Genética y Biología Molecular Centro Médico Country. Correspondencia: labgeneticaybiologia@cable.net.co

Palabras claves: enfermedad renal, Red Nacional de Transplantes, Haplotipos HLA.

Resumen: Dice el famoso adagio popular "Nadie sabe cuanto vale algo, hasta que lo pierde". Digo esto porque conozco de cerca el drama terrible de los 12.600 colombianos que hoy en día asisten a las unidades de diálisis de todo el país para soportar durante 4 horas diarias, 3 días a la semana, 365 días al año que un aparato filtre su sangre, pues sus riñones están impedidos definitivamente para hacerlo. Estos pacientes debido a diversos factores pierden sus riñones, quiero decir las funciones fisiológicas que este importantísimo órgano lleva a cabo de manera natural en las personas sanas. La función del Laboratorio de Genética y Biología Molecular, dentro de la 
red nacional de transplantes, es preparar la primera fase del transplante renal, de médula ósea y de otros órganos que ya es costumbre transplantar a nivel mundial como son corazón, hígado, páncreas, pulmón, hueso, cornea entre otros. Nuestro trabajo consiste en encontrar las diferencias o igualdades de un sistema genético llamado HLA entre el donante y receptor del órgano. Si las diferencias son muy grandes se corre el riego que se rechace el transplante, por esto se busca la mayor compatibilidad entre el donante y receptor. En compañía de la red nacional de transplantes y el Laboratorio de Genética y Biología Molecular se decidió adelantar un importantísimo estudio y nos dimos a la tarea de tabular y analizar 1.000 pacientes tipificados, tanto donantes como receptores, esto nos ha permitido conocer el panorama genético a nivel nacional del sistema HLA en Colombia. Inicialmente quisimos saber si existían diferencias significativas dentro de este sistema genético en la población de donantes y receptores y por esto comparamos los resultados de ambas poblaciones llegando a una gran conclusión: no existe ninguna asociación entre los genes HLA y la enfermedad renal dado que los estudios genéticos de las dos poblaciones en todos los genes analizados no presentan diferencias significativas. De todas maneras logramos deducir las frecuencias de los genes y los haplotipos del HLA, información valiosísima que irá a redundar en beneficio de todos los pacientes que hoy en día padecen de enfermedad renal porque de ahora en adelante y de acuerdo a la carga genética que cada uno porte, van a poder saber que tan fácil o difícil es conseguir un donante de órganos efectivo. Resaltemos aquí que esta información es valiosa para la Red Nacional de Transplantes, pues de ahora en adelante el cuerpo médico va a poder saber de antemano donde están las principales dificultades especialmente en la provincia para poder conseguir un donante de órganos cadavérico, que es la última solución para este grupo de colombianos que ha perdido la funcionalidad de sus riñones debido a una enfermedad renal.
8.

Identificación del Papiloma Virus Humano en mujeres que asisten al servicio de colposcopia de la Liga de Lucha Contra el Cáncer en la ciudad de Neiva.

\author{
Autores: Yenny Montenegro ${ }^{1}$, Beatriz Caldón ${ }^{1}$, Adriana Esteves $^{2}$ \\ Henry Ostos ${ }^{1}$ \\ Instituciones: ${ }^{1}$ Laboratorio de Medicina Genómica Universidad Sur \\ Colombiana de Neiva, ${ }^{2}$ Universidad del Rosario. \\ Correo electrónico: yenny_mmm@yahoo.com
}

Resumen: El presente estudio tuvo como objetivo identificar en mujeres que asisten al servicio de colposcopia de la Liga de Lucha contra el Cáncer de Neiva, la presencia de HPV mediante la estandarización de la técnica de Reacción en Cadena de la Polimerasa (PCR) para HPV y para la diferenciación de los sub-tipos 16 y 18 en las mujeres positivas para pipiloma virus. Se tomaron 58 muestras positivas para HPV según colposcopia, y como control negativo se le realizo el mismo procedimiento a 20 muestras de citología normal para determinar la especificidad de la técnica. Dada la ausencia de una prueba oro, la sensibilidad se calculo comparando con las biopsias. En la extracción de ADN se emplearon tres métodos, obteniendo una eficiencia de $83.3 \%$ con fenol Cloroformo, $48.7 \%$ con la técnica de Walboomers y $93.7 \%$ con la de Gómez y cols. Para la evaluación del ADN, a las muestras se les realizo la amplificación del loci AMELOGENINA obteniendo producto en 26/50, de las cuales, 21 fueron positivas para HPV y de las positivas para HPV, 16 fueron positivas para HPV 16 y 2 para 18 . En una mujer se encontraron los dos tipos, mientras que 4 fueron negativas para los dos. En conclusión, de forma similar a lo publicado, el tipo identificado con mayor frecuencia en esta muestra fue el HPV 16, hallado en el 76.2\% de las muestras positivas para HPV. Es importante mencionar que en cuatro pacientes no fue posible llevar a cabo la tipificación, lo que podría indicar la presencia de más tipos circulante de alto riesgo en nuestra población. Al correlacionar las variables no se hallaron diferencias significativas entre la presencia 
de HPV y el estadio de la enfermedad, lo que puede indicar que la sensibilidad de nuestra técnica es buena y puede ayudar a un diagnóstico temprano, objetivo final de este tipo de investigaciones.

\section{9.}

\section{Expresión génica de mecanismos moleculares implicados en la biosintesis del colesterol en un modelo animal}

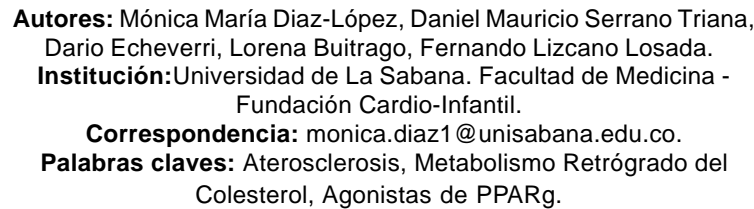

Resumen: Los eventos iniciales en la aterosclerosis están mediados a nivel de endotelio por la presencia de macrófagos, los cuales se transforman en células espumosas por la captación de lípidos. Actualmente, se han realizado estudios para conocer la vía de eflujo de colesterol de dichas células, con el fin de contrarrestar los efectos iniciales de la enfermedad. Se han encontrado que los agonistas de PPARg ofrecen una buena alternativa para modular estos efectos, por lo que son considerados una alternativa terapéutica en el manejo de estos eventos.

En el presente estudio se busco establecer en un modelo animal la incidencia de agonistas de PPARg(Rosiglitazona) sobre la expresión de algunos genes que están involucrados en la vía retrógrada del colesterol (ABC A1, LXRa) y eventos proinflama- torios en la aterosclerosis (ILb1), mediante RT-PCR. Este estudio experimental fue aprobado por el Comité de investigación de la Facultad de Medicina de la Universidad de La Sabana. Informamos resultados de 15 conejas que han ingresado al estudio. El grupo 1 (Control; $n=5$ ) de conejas sanas con dieta normal; el grupo $2(n=5)$ son conejas no ooforectomizadas con dieta hipercolesterolémica (suplemento de colesterol al $2 \%$ por un periodo de 16 semanas) y el grupo 3 $(n=5)$ son conejas ooforectomizadas quirúrgicamente con dieta hipercolesterolémica, que han recibido durante 5 semanas con Rosiglitazona $3 \mathrm{mg} / \mathrm{kg} /$ día. Se realizaron los sacrificios según las normas establecidas, y se extrajeron muestras de hígado, aorta y tejido graso, mantenidos en nitrógeno líquido hasta su maceración y almacenamiento. Posteriormente, se realizó la extracción de RNA y procedimiento de RTPCR semicuantitativa, empleando como gen housekeeping la b-actina. Encontrándose que efecto de la Rosiglitazonasi produjo un incremento en la expresión de los genes involucrados en el metabolismo reverso del colesterol (LXRa, ABCA1), mientras que se disminuyo la expresión de ILb1. Lo que nos permitió concluir que la RosiglitazonaÒ podría aumentar el eflujo de colesterol desde macrófagos de la pared arterial pues en este estudio observamos un aumento de la expresión de LXR y ABCA1, genes comprometidos en la vía retrógrada del colesterol. Por otro lado induce una disminución de ILb1, que está involucrado en los eventos iniciales pro-inflamatorios de la aterosclerosis. 